\title{
Cryopreservation of platelets: an in-vitro comparison of four methods
}

\author{
M ANN TAYLOR \\ From the South Western Regional Blood Transfusion Centre, Bristol BS10 5ND, UK
}

SUMMARY Platelets were cryopreserved in four different cryoprotectives-two intracellular (dimethylsulphoxide, glycerol) and two extracellular (hydroxyethyl starch, dextran). The platelets were evaluated according to their yields, hypotonic shock response, and serotonin uptake, which are useful parameters for establishing optimum storage conditions. Hydroxyethyl starch and dextran were found to be poor cryoprotectives while $5 \%$ dimethylsulphoxide was the most suitable.

Blood transfusion centres are under considerable pressure to produce an ever-increasing number of platelet concentrates for treating a wide variety of clinical conditions. The maximum shelf-life of platelet concentrates stored at $4^{\circ} \mathrm{C}$ or $22^{\circ} \mathrm{C}$ is 72 hours, which makes inventory control very difficult. The successful long-term cryopreservation of platelets, prepared on a large scale either from single or pooled donations or from donations collected from cell separators, would be a considerable advance. An HLA-typed platelet bank would also be invaluable for providing platelets for patients requiring HLA compatible platelets.

Much work has already been carried out towards establishing the optimum method for cryopreservation of platelets. Dimethylsulphoxide (DMSO) has been shown by many workers ${ }^{1-4}$ to be a suitable cryoprotective agent, while others ${ }^{56}$ have shown glycerol-glucose to be successful. With these methods the thawed platelets need to be washed to remove the cryoprotective before transfusion. Choudhury and Gunstone, ${ }^{7}$ however, described a method for freezing platelets using hydroxyethyl starch (HES) as a cryoprotective agent. The platelets could be transfused after thawing without prior washing. Eliminating the need to wash platelets before transfusion has many advantages, but Raymond et al. ${ }^{8}$ found that recovery of platelets preserved in $5 \%$ HES and $5 \%$ dextran was poor.

In this present study platelet cryopreservation was carried out using two intracellular (DMSO, glycerol) and two extracellular (HES, dextran) cryoprotective agents. Serotonin (5HT) uptake and hypotonic shock response (HSR) have been carried out on the cryo-

Accepted for publication 9 June 1980 preserved platelets as these tests are excellent for evaluating preserved platelets. ${ }^{9-13}$

\section{Methods}

PLATELET CONCENTRATE PREPARATIONS

Platelet-rich plasma (PRP) was prepared from fresh whole blood, collected in ACD anticoagulant, within six hours of collection by centrifuging at $2900 \mathrm{rpm}$ $(2260 \mathrm{~g})$ for $90 \mathrm{~s}$ at $22^{\circ} \mathrm{C}$ in a Damon PR6000 centrifuge with interior wind-shielded, swing-out head.

The PRP was acidified by adding $35 \mathrm{ml}$ ACD anticoagulant and then agitated to ensure mixing. The platelet concentrate (PC) was prepared by centrifuging the acidified PRP at $3500 \mathrm{rpm}(3000 \mathrm{~g})$ for $20 \mathrm{~min}$ at $22^{\circ} \mathrm{C}$. The platelet button was resuspended immediately in $20 \mathrm{ml}$ autologous plasma and the remaining acidified platelet-poor plasma (PPP) was retained for use in further processing of the platelets.

\section{CRYOPRESERVATION}

The platelets were frozen in polyolefin platelet freezing bags (Ucar blood freezing bags, Union Carbide). The bags were placed in an aluminium container for both freezing and storage. A Union Carbide controlled rate freezer was used to obtain the required freezing rates and the units were cooled to $-80^{\circ} \mathrm{C}$. Then they were transferred, in the aluminium containers, to the vapour phase of liquid nitrogen, where they were stored until required for reconstitution.

The platelet freezing methods were as follows.

(1) Cryopreservation in $4 \%(w / v)$ HES was carried out by the method of Choudhury and Gunstone.? Two volumes of $6 \%$ HES in normal saline (Plasma- 
steril MW 450000 , Fresenins, Bad Homburg, W. Germany) were added to one volume of platelet concentrate and the platelets were frozen at $1{ }^{\circ} \mathrm{C} / \mathrm{min}$. The platelets were ready for testing immediately after thawing in a $37^{\circ} \mathrm{C}$ water bath.

(2) Dextran (MW 10000 , Sigma Co Ltd) was mixed with phosphate buffered saline to make a final concentration of $15 \%(\mathrm{w} / \mathrm{v})$. After preparing the platelet concentrate all the acidified plasma was removed and the platelets were suspended in $20 \mathrm{ml}$ $15 \%$ dextran and then frozen at $5^{\circ} \mathrm{C} / \mathrm{min}$ to $-80^{\circ} \mathrm{C}$. After cryopreservation the platelets were thawed at $37^{\circ} \mathrm{C}$ and were ready for testing.

(3) The method used for cryopreserving platelets in glycerol-sugar was that of Herve et al. ${ }^{614}$ Three different glycerol-sugar concentrations in isotonic saline were used: $3 \%$ glycerol $(v / v) 3 \%$ glucose $(\mathrm{w} / \mathrm{v}), 5 \%$ glycerol (v/v) $4 \%$ sorbitol (w/v), and $6 \%$ glycerol $(\mathrm{v} / \mathrm{v}) 3 \%$ glucose $(\mathrm{w} / \mathrm{v})$. The platelets were frozen at $10^{\circ} \mathrm{C} / \mathrm{min}$ to $-3^{\circ} \mathrm{C}$ and then at $35^{\circ} \mathrm{C} / \mathrm{min}$ to $-80^{\circ} \mathrm{C}$. After thawing autologous PPP was added to the platelets. They were spun to pellet the platelets, all the plasma was removed, and the platelets were resuspended in autologous PPP.

(4) Platelets were cryopreserved in 5\% DMSO by a method similar to those published. ${ }^{4}{ }^{15}$ DMSO $10 \%$ in autologous PPP was added slowly and with agitation to the PC. The platelets in $5 \%$ DMSO were frozen at $1{ }^{\circ} \mathrm{C} / \mathrm{min}$. They were thawed in a $37^{\circ} \mathrm{C}$ water bath and about $100 \mathrm{ml}$ autologous, acidified PPP was added slowly and with gentle agitation. This PRP was spun to pellet the platelets, all the plasma was removed and the platelets were resuspended in $20 \mathrm{ml}$ autologous acidified plasma. Platelets cryopreserved in $5 \%$ DMSO but frozen by placing them immediately in the vapour phase of liquid nitrogen were prepared and resuspended as above. Residual DMSO levels were measured by gas liquid chromatography using a Pye GCD machine. The stationary phase was $10 \%$ polypropylene glycol adipate with a column temperature of $170^{\circ} \mathrm{C}$. DMSO in plasma was extracted with acetone to precipitate the protein before being added to the column. ${ }^{16}$
IN-VITRO TESTING

Platelet counts were determined on the original freshly prepared platelet concentrates and on the reconstituted cryopreserved platelets using a Technicon Autocounter (dark ground illumination). From these counts and the PC volumes the percentage yield of platelets could be determined.

The method used for serotonin uptake was based on the method of Weiss et al.17 as described by Tandy and Taylor. ${ }^{13}$ Tandy and Taylor ${ }^{13}$ showed that for fresh platelets the concentration of ${ }^{14} \mathrm{C}$ serotonin was in excess when $20 \mathrm{~min}$ incubation at $37^{\circ} \mathrm{C}$ and a platelet count of $\widehat{\Lambda} 200 \times 10^{9} / 1$ were used.

The method for HSR was based on the method of Valeri et al. ${ }^{10}$ as described by Tandy and Taylor. ${ }^{13}$ The results were calculated relative to fresh platelets.

\section{Results}

The yields of platelets obtained with the four cryoprotective reagents are shown in Table 1. Platelets cryopreserved in DMSO or glycerol had higher yields than those in HES. For the platelets cryopreserved in dextran the count recoveries on thawing were quite high. However, when the platelets were washed to remove the dextran and resuspended in autologous PPP the platelet count fell considerably. This large reduction in numbers during washing was not observed with the other cryoprotectives (unpublished results).

Serotonin uptake was measured over one hour (Table 2). For the platelets frozen in DMSO, glycerol, or dextran a platelet count of about $200 \times 10^{9} / 1$ was used in the assay. Since the count recovery was low for platelets preserved in $4 \%$ HES the average count used in this assay was $100 \times 10^{9} / 1$. None of the platelet samples recovered after cryopreservation took up so much serotonin as fresh platelets. The highest uptake obtained was for platelets cryopreserved in DMSO.

Relative HSR determinations are shown in the Figure. Also shown are the relative HSRs for fresh platelets incubated at room temperature for one hour

Table 1 Mean $( \pm S D)$ platelet yields with four different cryoprotective agents

\begin{tabular}{|c|c|c|c|c|c|c|c|}
\hline & \multirow[t]{2}{*}{$4 \% H E S$} & \multirow[t]{2}{*}{$15 \%$ Dextran } & \multicolumn{3}{|l|}{ Glycerol-sugar } & \multicolumn{2}{|c|}{$5 \% D M S O$} \\
\hline & & & $\begin{array}{l}3 \% \text { Glycerol } \\
3 \% \text { glucose }\end{array}$ & $\begin{array}{l}5 \% \text { Glycerol } \\
4 \% \text { sorbitol }\end{array}$ & $\begin{array}{l}6 \% \text { Glycerol } \\
3 \% \text { glucose }\end{array}$ & $l^{\circ} \mathrm{C} / \min$ & Vapour phase \\
\hline Yield (\%) & 11 & $\begin{array}{l}57 \pm 11^{*} \\
21 \pm 9 \dagger\end{array}$ & $30 \pm 13$ & $32 \pm 10$ & $51 \pm 15$ & $54 \pm 20$ & $42 \pm 9$ \\
\hline $\begin{array}{l}\text { Number of units tested- } \\
\text { for all assays }\end{array}$ & 20 & 21 & 20 & 14 & 7 & 18 & 18 \\
\hline
\end{tabular}


Table 2 Mean $( \pm S D)$ serotonin uptake over one hour by platelets cryopreserved in four different cryoprotective agents

\begin{tabular}{|c|c|c|c|c|c|c|c|c|c|}
\hline \multirow{4}{*}{ 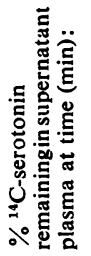 } & & \multirow[t]{2}{*}{$4 \% H E S^{*}$} & \multirow[t]{2}{*}{$15 \%$ Dextran } & \multicolumn{3}{|l|}{ Glycerol-sugar } & \multicolumn{2}{|c|}{$5 \%$ DMSO } & \multirow{2}{*}{$\begin{array}{l}\text { Fresh } \dagger \\
\text { platelets } \\
(n=11)\end{array}$} \\
\hline & & & & $\begin{array}{l}3 \% \text { Glycerol } \\
3 \% \text { glucose }\end{array}$ & $\begin{array}{l}5 \% \text { Glycerol } \\
4 \% \text { sorbitol }\end{array}$ & $\begin{array}{l}6 \% \text { Glycerol } \\
3 \% \text { glucose }\end{array}$ & $1^{\circ} \mathrm{C} / \min$ & Vapour phase & \\
\hline & \multirow{2}{*}{$\begin{array}{r}0 \\
10 \\
20 \\
30 \\
60\end{array}$} & $\begin{array}{l}100 \\
100 \\
100\end{array}$ & $\begin{array}{l}100 \\
94 \pm 4 \\
92 \pm 4\end{array}$ & $\begin{array}{l}100 \\
95 \pm 5\end{array}$ & $84 \pm 7$ & $87 \pm 8$ & $\begin{array}{l}100 \\
62 \pm 26 \\
44 \pm 23\end{array}$ & $\begin{array}{l}100 \\
72 \pm 29 \\
61 \pm 15\end{array}$ & $\begin{array}{l}100 \\
34 \cdot 5 \pm 6 \cdot 4 \\
16 \pm 3 \cdot 2\end{array}$ \\
\hline & & 100 & $87 \pm 7$ & $\begin{array}{l}85 \pm 6 \\
69 \pm 19\end{array}$ & $\begin{array}{l}65 \pm 11 \\
52 \pm 15\end{array}$ & $\begin{array}{l}73 \pm 14 \\
62 \pm 15\end{array}$ & $28 \pm 17$ & $28 \pm 16$ & \\
\hline
\end{tabular}

*Platelet counts for 5 HT assay $\simeq 200 \times 10^{\%} / 1$ except $4 \%$ HES where platelet count $\simeq 100 \times 10^{\%} / 1$.

†From Tandy and Taylor. ${ }^{13}$

in the presence of cryoprotective, but without freezing, and then washed and resuspended. The HSR was not carried out for platelets cryopreserved in $6 \%$ glycerol and $3 \%$ glucose and dextran as these compounds substantially reduced the HSR even before cryopreservation (Figure). The frozen platelets cryopreserved in $5 \%$ DMSO with a freezing rate of $1^{\circ} \mathrm{C} / \mathrm{min}$ gave the highest response, whereas freezing with $4 \%$ HES gave no response at all.

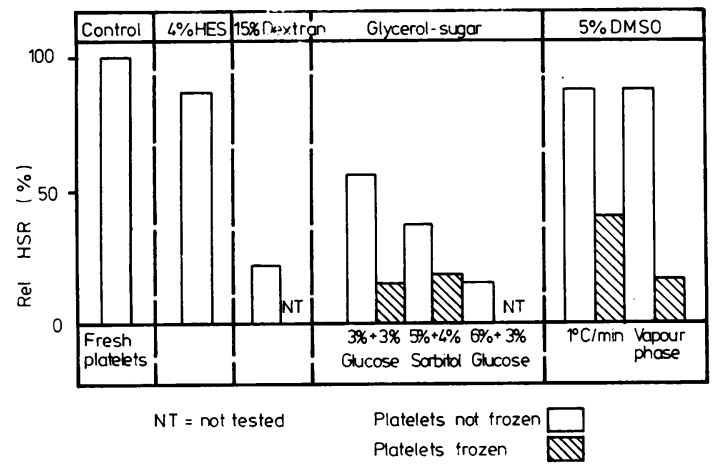

Relative hypotonic shock responses.

Altering the glycerol-sugar concentrations had little effect on the serotonin uptake of the cryopreserved platelets. The effect of glycerol on HSR increases with increase in glycerol concentration (Figure) such that there is little HSR for platelets incubated with $6 \%$ glycerol and $3 \%$ glucose. The relative HSR for platelets cryopreserved in 5\% glycerol and $4 \%$ glucose was marginally better than for platelets in $3 \%$ glycerol and $3 \%$ glucose. While there was little difference in the percentage yield of platelets preserved at these concentrations, the best yeilds were obtained when $6 \%$ glycerol and $3 \%$ glucose was used (Table 1). Other glycerol-sugar concentrations (in the range 5\%-10\% glycerolglucose and $3 \%-6 \%$ glycerol-sorbitol) were tried but the results were not improved (unpublished results).
Of the four cryoprotective agents tested DMSO appears the most suitable. There is little difference between the percentage yield (Table 1) and the serotonin uptake (Table 2) for the platelets cryopreserved in $5 \%$ DMSO with freezing either at a controlled rate of $1^{\circ} \mathrm{C} / \mathrm{min}$ or by placing directly into the vapour phase of liquid nitrogen. However, the relative HSR is noticeably higher for platelets frozen at $1^{\circ} \mathrm{C} / \mathrm{min}$ (Figure). Gas liquid chromatography (GLC) was carried out to determine the residual DMSO concentration in cryopreserved platelets, recovered and prepared for transfusion. Twelve units were tested and a mean value of $113 \mathrm{mg}( \pm 29 \mathrm{mg}$, $1 \mathrm{SD})$ DMSO per unit of platelets was found, which is about $5 \%$ of the original DMSO.

\section{Discussion}

The results of this present study have indicated that hydroxyethyl starch and dextran are poor cryoprotective agents for the long-term storage of platelets. Choudhury and Gunstone ${ }^{7}$ reported satisfactory results using HES but their results are also at variance with Odink and Sprokholt. ${ }^{19}$ Different molecular weight HESs (150 000-450 000) and faster freezing rates (from $4^{\circ} \mathrm{C} / \mathrm{min}$ to direct immersion in liquid nitrogen) were tried in this present study but they also gave poor results (unpublished results). In the present work the methods of testing the platelets in vitro differed from those used by Choudhury and Gunstone. ${ }^{7}$ Platelet factor 3 availability was not determined because it was considered unsuitable for monitoring platelet production and storage. ${ }^{13}$

Choudhury and Gunstone counted platelets using the Thrombocounter (Coulter counter), which counts all particles within a chosen size range whether they are intact platelets or not. In this work and previously ${ }^{13}$ a Technicon system was used which is based on dark ground illumination of platelets and not size. Ammonia, a dispersant, is used in the system to clear cell debris, thus making the counts more accurate. Vecchione and Valeri20 reported a difference in counts obtained when the Technicon 
and Coulter counters were used to count cryopreserved platelets. The platelet counts using the Technicon system were about $65 \%$ of those obtained with the Coulter when resuspended platelets which had been cryopreserved in $5 \%$ DMSO were counted. A more sensitive method for HSR was also used in this present study and previously. ${ }^{13}$

Platelets cryopreserved in glycerol gave lower yields and poor in-vitro viability compared with those cryopreserved in DMSO. Attempts were made to freeze platelets in glycerol at $30^{\circ} \mathrm{C} / \mathrm{min}^{5}$ but a consistent freezing curve could not be obtained. Again, the method of counting platelets in this present study was different from those of other workers using glycerol. 561421 Herve et al. ${ }^{14}$ used the Coulter while the others counted the platelets in a haemocytometer chamber by phase contrast microscopy. The platelet recoveries were high, four of the 17 units reported by Dayian and Pert ${ }^{21}$ having recoveries over $100 \%$. They reported that most of the platelet loss occurred during processing and not freezing. Manual counting was not carried out in this present study because of difficulties in identifying the intact platelets by phase microscopy in some samples which had been cryopreserved. It has been reported ${ }^{521}$ that platelets cryopreserved in glycerol show a high uptake of serotonin after $30 \mathrm{~min}$ incubation. However, these workers used a much lower concentration of serotonin in their test than is used in the present study and the platelet count of the test samples was either not specified $^{21}$ or covered a wide range. ${ }^{5}$ This raises the possibility that in their experiments the serotonin concentration may not have been in excess for the total time of incubation with fresh platelets. The serotonin concentration used in this work and previously ${ }^{13}$ was chosen to ensure serotonin was in excess. Neither Herve et al. ${ }^{614}$ nor Dayian and coworkers ${ }^{51}$ used the HSR test.

Kim and Baldini ${ }^{9}$ have shown that glycerol has a marked effect on HSR and the effect increases with increasing glycerol concentration. Bakry and $\mathrm{McGill}^{22}$ reported that the ultrastructural integrity appeared to be maintained in platelets incubated in 3\% glycerol. They were discoid shaped, contained normal numbers of granules, and their surface membranes appeared intact. However, at $6 \%$ glycerol and higher the number and electron density of the granules were significantly reduced. Meryman and Burton $^{23}$ and $\mathrm{Kahn}^{24}$ state that other workers have found cryopreservation of platelets using glycerol to be unsuccessful.

In-vitro testing of platelets cryopreserved in 5\% DMSO and frozen at $1^{\circ} \mathrm{C} / \mathrm{min}$ has been carried out by some laboratories, although the exact methods used for each test has varied. The relative HSR of $38 \%$ reported here compares favourably with the relative HSR of $44 \%$ reported by $\mathrm{Kim}$ and Baldini ${ }^{15}$ and $36 \%$ reported by Odink and Brand. ${ }^{11}$ The serotonin uptake compared with fresh, control platelets was $38 \%$ after two hours ${ }^{15}$ and $58 \%$ after 10 minutes in this report. Odink and Brand ${ }^{11}$ reported a relative serotonin uptake velocity of $23 \%$. Valeri et al. ${ }^{10}$ reported a mean total in-vitro recovery of $43 \pm 10 \%$ for platelet cryopreservation in 5\% DMSO.

Many workers have transfused platelets which have been cryopreserved in 5\% DMSO using a controlled rate of freezing. Satisfactory in-vivo results have been obtained. Handin and Valeri ${ }^{1}$ showed that in normal volunteers the recovery of frozen platelets was $47 \% \pm 3 \%(70 \%$ of the value for fresh platelets) with a lifespan of $8.8 \pm 0.3$ days $(8.9 \pm 0.3$ days for fresh platelets). Kim and Baldini $^{2}$ showed that platelets had a mean viability index of $69 \%$, while Odink and Brand ${ }^{11}$ showed cryopreserved platelets had a transfusion efficiency of $36 \%$. They both showed that on infusion some cryopreserved platelets have a short lifespan while the rest survived almost normally. Results from transfusion of cryopreserved platelets to patients with leukaemia 25 and thrombocytopenia ${ }^{3} 4$ showed that the platelets can circulate and function haemostatically. Schiffer et al. ${ }^{25}$ transfused with satisfactory results platelets cryopreserved in 5\% DMSO and frozen by placing directly into the vapour phase of liquid nitrogen, but they did not provide sufficient data to indicate which freezing rate was preferable. Platelets frozen by placing directly into a $-80^{\circ} \mathrm{C}$ freezer in $4 \% \mathrm{DMSO}^{26}$ had an in-vivo recovery of $35 \%$ and a lifespan of 6.4 days $(65 \%$ and 8 days for fresh platelets), while with $6 \% \mathrm{DMSO}^{18}$ a $45 \%$ recovery and a lifespan of 8.5 days was shown.

In the first experiments with transfusion of DMSO-preserved platelets the DMSO was not removed from the thawed platelets before transfusion and there were side effects from the infusion. ${ }^{27}$

Handin and Valeri ${ }^{1}$ showed that platelet recovery in vivo was adversely affected by the presence of DMSO at the time of transfusion. In addition, since the long-term toxicity of large volumes of intravenous DMSO is uncertain, the platelets are now washed to remove the DMSO before infusion. In the present work only $5 \%$ of the DMSO remained. $\mathrm{Kim}$ and Baldini ${ }^{16}$ have also reported low concentrations of residual DMSO-a 20-ml PC contained $45 \mathrm{mg}(21-78 \mathrm{mg})$ of residual DMSO after a single washing with 120-150 $\mathrm{ml}$ PPP.

Kim and Baldini ${ }^{9}$ showed that $5 \%$ DMSO had a definite though not large influence on the reversal reaction, while $10 \%$ and $15 \%$ had a greater effect. Odink and Sprokholt ${ }^{28}$ showed that incubation with $5 \%$ DMSO had more effect on HSR than on the serotonin uptake velocity. Murphy et al. ${ }^{3}$ reported 
that as the DMSO concentration increased the theoretical increase in cryoprotective effect was apparently offset by the agents inherent toxicity and they concluded that $5 \%$ DMSO was optimal.

From the results presented here DMSO is clearly the most suitable cryoprotective even though many platelets are lost during the process. Cryopreservation of platelets using $5 \%$ DMSO may be of great use when fresh platelets are not available and when compatible platelets are required. Platelets cryopreserved in $5 \%$ DMSO in this laboratory are being transfused and a further report will follow.

I thank Mr J Allen for the gas liquid chromatography work and Dr ID Fraser for his aid in preparing this paper.

\section{References}

${ }^{1}$ Handin RI, Valeri CR. Improved viability of previously frozen platelets. Blood 1972;40:509-13.

${ }^{2}$ Kim BK, Tanoue K, Baldini MG. Storage of human platelets by freezing. Vox Sang 1976;30:401-11.

${ }^{3}$ Murphy S, Sayer SN, Abdou NL, Gardner FH. Platelet preservation by freezing. Use of dimethylsulphoxide as cryoprotective agent. Transfusion 1974;14:139-44.

${ }^{4}$ Schiffer CA, Aisner J, Wiernik PH. Clinical experience with transfusion of cryopreserved platelets. BrJ Haematol 1976;34:377-85.

${ }^{5}$ Dayian G, Rowe AW. Cryopreservation of human platelets for transfusion; a glycerol-glucose moderate rate cooling procedure. Cryobiology 1976;13:1-8.

${ }^{6}$ Herve $\mathrm{P}$, Masse M, Kieffer Y, et al. Cryoconservation des plaquettes dans l'azote liquide en presence de glycerolglucose. Colloque de Cryoimmunologie, Dijon, 1976. INSERM, 62, 163-70.

${ }^{7}$ Choudhury C, Gunstone MJ. Freeze preservation of platelets using hydroxyethyl starch (HES); a preliminary report. Cryobiology 1978;15:493-501.

${ }^{8}$ Raymond SL, Pert JM, Dodds WJ. Evaluation of platelet cryopreservation technique by isolated kidney perfusion. Transfusion 1975;15:219-25.

${ }^{9} \mathrm{Kim}$ BK, Baldini MG. The platelet response to hypotonic shock. Its value as an indicator of platelet viability after storage. Transfusion 1974;14:130-8.

10 Valeri CR, Feingold H, Marchionni LD. The relation between response to hypotonic stress and the ${ }^{51} \mathrm{Cr}$ recovery in vivo of preserved platelets. Transfusion 1974;14:331-7.

11 Odink J, Brand A. Platelet preservation V survival, serotonin uptake velocity and response to hypotonic stress of fresh and cryopreserved human platelets. Transfusion 1977;17:203-9.

12 Hardeman MR, Heynens Carina JL. Storage of human blood platelets. The serotonin uptake and hypotonic shock response as in-vitro viability test. Thromb Haemostas $1976 ; 32: 405-16$.

${ }^{13}$ Tandy NP, Taylor MA. Platelet concentrates for transfusion: control of production and storage. Med Lab Sci 1980;37:127-36.

14 Herve P, Masse P, Porton G, et al. Méthode de cryoconservation des plaquettes à $196^{\circ} \mathrm{C}$. Rev Fr Transfus Immunohématol 1977;20:603-15.

${ }^{15} \mathrm{Kim}$ BK, Baldini MG. Biochemistry, function and haemostatic effectiveness of frozen human platelets. Proc Soc Exp Biol Med 1974;145:830-5.

${ }^{16} \mathrm{Kim}$ BK, Baldini MG. Preservation of viable platelets by freezing. Effect of plastic containers. Proc Soc Exp Biol Med 1973;142:345-50.

17 Weiss HJ, Tschopp TB, Rogers J, Brand H. Studies of platelet 5-hydroxytryptamine (serotonin) in storage pool disease and albinism. J Clin Invest 1974;54:421-32.

18 Valeri CR, Feingold H, Marchionni LD. A simple method for freezing human platelets using $6 \%$ dimethylsulphoxide and storage at $-80^{\circ} \mathrm{C}$. Blood 1974;43:131-6.

19 Odink J, Sprokholt R. Platelet preservation. I. The use of decrease in light absorbance as a screening method in cryopreservation studies on human platelets. Cryobiology 1977;14:519-28.

20 Vecchione JJ, Valeri CR. Status report on cryopreservation of human platelets. Proceedings of the Haemonetics Research Institute advanced component seminar. Boston, Massachusetts, 1979.

${ }^{21}$ Dayian G, Pert JH. A simplified method for freezing human blood platelets in glycerol-glucose using a statically controlled cooling rate device. Transfusion 1979;19:255-60.

22 Bakry M, McGill M. Glycerol effects on human platelet volume shape and ultrastructure. Cryobiology 1977; 14:699.

${ }^{23}$ Meryman HT, Burton JL. Cryopreservation of platelets. In: The Blood Platelet in Transfusion Therapy. New York: Alan R Liss, 1978:153-65.

${ }^{24} \mathrm{Kahn}$ RA. Discussion. In: The Blood Platelet in Transfusion Therapy. New York: Alan R Liss, 1978:192.

${ }^{25}$ Schiffer CA, Aisner J, Wiernik PH. Frozen autologous platelet transfusion for patients with leukaemia. $N$ Engl J Med 1978;299:7-12.

${ }^{26}$ Kahn RA, Dionne J, Becker G. A procedure for the freeze preservation of platelets. Cryobiology 1975;12:565.

27 Djerassi I, Farber G, Roy A, Cavins J. Preparation and in vivo circulation of human platelets preserved with combined dimethylsulphoxide and dextrose. Transfusion $1966 ; 6: 572-6$.

28 Odink J, Sprokholt R. Platelet preservation. III. The influence of dimethylsulphoxide and cooling conditions on serotonin uptake velocity and response to hypotonic stress of human platelets. Thromb Haemostas 1976; 36:192-9.

Requests for reprints to: MA Taylor, National Blocd Transfusion Service, South Western Regional Transfusion Centre, Southmead Road, Bristol BS10 5ND. 